Supplement of Biogeosciences, 15, 471-490, 2018

https://doi.org/10.5194/bg-15-471-2018-supplement

(C) Author(s) 2018. This work is distributed under

the Creative Commons Attribution 3.0 License.

(c) (1)

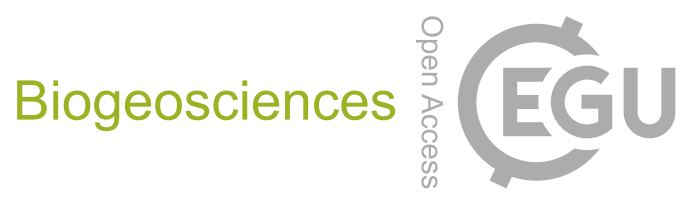

Supplement of

\title{
Carbon mineralization in Laptev and East Siberian sea shelf and slope sediment
}

Volker Brüchert et al.

Correspondence to: Volker Brüchert (volker.bruchert@geo.su.se)

The copyright of individual parts of the supplement might differ from the CC BY 3.0 License. 
Supplementary Table 1. Boundary conditions for porewater modelling

\begin{tabular}{|c|c|c|c|}
\hline Station & 1 & 23 & 30 \\
\hline Domain (top, bottom) cm & $-0.5,32.5$ & $-0.5,32.5$ & $-0.5,22.5$ \\
\hline \multicolumn{4}{|l|}{ Boundary conditions for concentrations } \\
\hline \multicolumn{4}{|l|}{ Top } \\
\hline $\mathrm{O}_{2}(\mu \mathrm{M})$ & 346 & 325 & 309 \\
\hline $\mathrm{DIC}(\mu \mathrm{M})$ & 2300 & 2442 & 2367 \\
\hline $\mathrm{Mn}^{2+}(\mu \mathrm{M})$ & 0.04 & 0.21 & 0.18 \\
\hline $\mathrm{Fe}^{2+}(\mu \mathrm{M})$ & 0.26 & 0.37 & 0.28 \\
\hline \multicolumn{4}{|l|}{ Bottom } \\
\hline $\mathrm{O}_{2}(\mu \mathrm{M})$ & $213(6 \mathrm{~cm})$ & 0 & 0 \\
\hline $\mathrm{DIC}(\mu \mathrm{M})$ & 3378 & 4853 & 6436 \\
\hline $\mathrm{Mn}^{2+}(\mu \mathrm{M})$ & 0.07 & 47.2 & 125.5 \\
\hline $\mathrm{Fe}^{2+}(\mu \mathrm{M})$ & 0.1 & 74.9 & 123.9 \\
\hline \multicolumn{4}{|l|}{ Molecular diffusion coefficient $\left(10^{-6} \mathrm{~cm}^{2} \mathrm{sec}^{-1}\right)$} \\
\hline $\mathrm{O}_{2}$ & 0.99 & 0.99 & 1.00 \\
\hline DIC (weighted $\mathrm{CO}_{2} / \mathrm{CO}_{3}{ }^{2-} / \mathrm{HCO}_{3}{ }^{-}$) pH 8.2 & 4.85 & 4.86 & 4.89 \\
\hline $\mathrm{Mn}^{2+}$ & 3.22 & 3.22 & 3.20 \\
\hline $\mathrm{Fe}^{2+}$ & 3.34 & 3.34 & 3.32 \\
\hline Porosity range (top, bottom) & $1 ; 0.6$ & $1 ; 0.5$ & $1 ; 0.55$ \\
\hline Bioturbation coefficient $\left(10^{-4} \mathrm{~cm}^{2} \mathrm{sec}^{-1}\right)$ & 0.00 & 0.00 & 0.00 \\
\hline Bioirrigation coefficient $\left(10^{-4} \mathrm{~cm}^{2} \mathrm{sec}^{-1}\right)$ & 0.00 & 0.00 & 0.00 \\
\hline D0 O2 & 0.99 & 1.00 & 0.99 \\
\hline DO HCO3- & 9.0 & 9.0 & 9.0 \\
\hline $\mathrm{DO} \mathrm{NH} 4+$ & 4.9 & 4.9 & 4.9 \\
\hline $\mathrm{HCO} 3-/ \mathrm{NH} 4+$ & 0.54 & 0.54 & 0.55 \\
\hline $\mathrm{K} \mathrm{NH} 4+$ & 1.3 & 1.3 & 1.3 \\
\hline Correction factor for DIC/NH4 plots & 2.37 & 0.70 & 0.71 \\
\hline
\end{tabular}




\begin{tabular}{ccc}
\hline $\mathbf{4 5}$ & $\mathbf{5 3}$ & $\mathbf{6 3}$ \\
\hline$-0.5,16.5$ & $-0.5,20.5$ & $-0.5,45$ \\
\hline & & \\
361 & 350 & 285 \\
2576 & 2494 & 2425 \\
0.07 & 0.49 & 19.76 \\
0.51 & 0.52 & 0.74 \\
& & \\
0 & 0 & 0 \\
4802 & 3291 & 6250 \\
313.5 & 222.3 & 115.3 \\
134.0 & 214.8 & 182 \\
\hline & & \\
\hline 1.01 & 1.00 & 1.01 \\
4.97 & 4.89 & 4.94 \\
3.14 & 3.20 & 3.17 \\
3.26 & 3.32 & 3.28 \\
\hline $1 ; 0.5$ & $1 ; 0.6$ & $1 ; 0.52$ \\
\hline 0.00 & 0.00 & 0.00 \\
\hline 0.00 & 1.00 & 0.00 \\
\hline & &
\end{tabular}

$\begin{array}{ccc}0.97 & 0.99 & 0.98 \\ 8.8 & 9.0 & 8.9 \\ 5.0 & 4.9 & 4.9 \\ 0.57 & 0.55 & 0.56 \\ 1.3 & 1.3 & 1.3 \\ 0.73 & 0.71 & 0.72\end{array}$

